\title{
ARCHIVE FOOTAGE IN NEW PROGRAMMES
}

\author{
PRESENTATIONAL ISSUES AND \\ PERSPECTIVES
}

\author{
Steve Bryant \\ BFI National Archive \\ J.Paul Getty Jnr Conservation Centre \\ Kingshill Way \\ Berkhamsted \\ HP4 3TP \\ United Kingdom \\ Steve.Bryant@bfi.org.uk
}

\begin{abstract}
Archivists have traditionally been concerned about what they have seen as incorrect usage of archival footage in new documentaries, but changing technologies and programme-making conventions have made this inevitable. This paper considers aspects of these changes, focussing particularly on the issue of how the introduction of widescreen television affected and continues to affect the aspect ratios in which archival materials are presented, using examples from recent and contemporary television documentaries from Britain and the USA.
\end{abstract}

Keywords: archives; documentaries; aspect ration.

How much does it matter if archive footage is 'misused' in a new production? If it falsifies evidence - certainly. If it gives a misleading picture of the past - maybe. But what if the misuse is a case of incorrect technical presentation? Or if a new context is being created for aesthetic reasons? Film and television archivists are conditioned to ensure, as far as it is in their power, that the materials in their custody are preserved ${ }^{1}$ and re-presented in a condition as close to the original as possible, but technologies and film and programme-making conventions change, and as they change, so attitudes to what archivists may regard as the 'correct' re-use of materials change with them, led by innovation and error. This paper will consider aspects of such changes, focussing particularly on the issue of how the introduction of widescreen television affected and continues to affect the aspect ratios in which archival footage is presented, using examples from recent and contemporary television documentaries made in Britain and the USA. It is written from the perspective of a television archivist, involved in both the preservation of materials and their supply for re-use in new programmes for the past four decades, and seeks not to propose strict guidelines, or to suggest that archivists should seek to intervene in the programme-making process when it comes to the question of what they may or may not think is an appropriate use of the material in their custody, but to trace changing attitudes and approaches. Although the question of ratios may not be uppermost in the concerns of the programme maker, the television historian needs to be aware of these issues, and the choices the programme makers have made, both when studying programmes which have re-used archival materials and when considering how archival materials have been re-used in new programming.

1 Archives will attempt to acquire as much original material as possible. If the archive is part of a broadcaster or production company, this will be easier, but national archives are the more common repositories of historic footage. Generally, material shot and preserved on film, will conform to original specifications, unless changes have been made as part of the printing process, but once the image enters the video or digital realm and is subject to further duplication, care has to be taken to note changes to technical specifications which may have occurred. 
The inclusion of archival footage in new television programmes has thrown up technical, aesthetic and ethical issues from the earliest days. From the 1960s to the 1980s, film from the first two decades of the medium would regularly be shown at the wrong speed, simply because it was often cut into a film documentary shot and designed to be shown at 24 or 25 frames a second. The similar misuse of silent comedy film was tolerated partly because it looked funnier to see the Keystone Cops performing their antics at breakneck speed - so the impression was given that the Edwardians moved faster than modern people. And, of course, old film had to be scratched and jumpy, and that is still the convention used when such footage is faked for comic effect in modern productions. In Britain, it took the growing appreciation of silent cinema fostered by Kevin Brownlow and David Gill, especially through the Thames Silents, as well as constant complaints by archivists from the British Film Institute, the Royal Television Society and elsewhere, to affect the programme makers' approach. Nowadays, with a strong focus on restored images and the creation of aesthetically beautiful documentaries by the likes of Ken Burns, the problem rarely, if ever, arises.

An altogether different problem was the inaccurate use of historic film: when the commentary is telling you one thing, but the film you are seeing is showing you something else, or, in the worst case, when you are watching a fictional recreation, maybe from a feature film, being passed off as a factual record. Professional historians were naturally very critical of such practices and the highly influential series The World at War (Thames Television, 1973-4) was rightly proud of the fact that its use of archive footage was carefully researched and that it made it clear when the viewer was seeing something that was reconstruction rather than actuality. One of the producers on that series, Jerry Kuehl, was prominent amongst those who regularly brought attention to the misattribution of historic footage in television documentaries, yet he also later acknowledged that the aim of the documentary producer was very different from that of the academic historian, as the TV history documentary "is not the doctoral dissertation but the reflective essay in which nothing is said recklessly but in which the flow of the text is not burdened with a scholarly apparatus either." ${ }^{2}$ The use of archive footage should not, thus, be seen as evidentiary, but illustrative and, while it should certainly not be deliberately misleading, a certain increasing latitude as to how it is presented seems to have developed over time.

Much the same also applies to the use of reconstruction. Once frowned upon by the makers of 'serious' history documentaries, it is now commonplace. As the amount of interesting historic footage not already used began to dwindle and as the number of interesting stories without relevant accompanying footage grew, so recourse to reconstruction became commonplace, even for leading producers such as Laurence Rees, who had previously foresworn it in series such as The Nazis: a Warning From History (BBC, 1997), then used it discreetly (Auschwitz: the Nazis and the Final Solution, BBC, 2005) and eventually built a series around it (World War II: Behind Closed Doors: Stalin, the Nazis and the West, BBC, 2008). Even the labelling of reconstructed sequences as 'reconstruction' is disappearing, as though the audience is treated as being media-savvy enough to know the difference between archive footage and modern reconstruction - and it probably doesn't really matter if they don't. In the centenary years of World War I, a conflict with precious little genuine combat footage, this is particularly evident.

While most of the history documentaries considered so far have utilised footage from traditional film archives, the main recent growth has, not unnaturally, been in subjects from the television era, as that era moves from being 'the recent past' to becoming 'history'. This has been particularly evident as the fiftieth anniversaries of events which took place in the 1960s have occurred - not just because of the dramatic nature of that decade, but because of the amount of material that has survived, both on film and on videotape, much of it still unfamiliar, even in well-covered subject areas. CNN's series The Sixties (2014) was particularly remarkable for uncovering a wealth of fascinating footage and eschewing the more familiar - the episode on the assassination of President Kennedy was particularly remarkable while the seemingly constant flow of excellent documentaries on civil rights, from Eyes on the Prize (PBS, 1987) to Freedom Summer ${ }^{3}$ (American Experience, PBS, 2014), is fuelled by extensive local television archives.

2 Jerry Kuehl, "History on the Public Screen II," in New Challenges for Documentary, Alan Rosenthal and John Corner, eds., $2^{\text {nd }}$ Edition, Manchester University Press, 2005, p 379.

3 The links to moving image sources on You Tube or broadcasters' websites in this paper are functioning at the time of writing, but are potentially subject to subsequent alteration or disappearance. Where possible, links to complete versions of the programmes cited have been provided, but in some cases the links are to sites which only contain extracts or trailers, or require payment for full viewing. Stills are provided for some of the items cited, where the presentation of archive material in different aspect ratios can be illustrated, but do not represent the point being made as effectively as the video would. Ironically, access to an archive of materials does not easily facilitate the provision of extracts, as it is incumbent on the archivist, as custodian of the materials, to be particularly respectful of copyright restrictions. In the case of this paper, the fact that many of the examples being cited are US productions complicates the issue still further. 
For this archivist, the biggest issue of recent years concerning the presentation of archive footage, though one of the least remarked, is the question of aspect ratio. When the shape of the TV screen changed from 4:3 to 16:9, this issue became acute, especially when the older material was being integrated into a new production made in widescreen. The re-use of all past television material, as well as historical documentary material and feature films shot in the academy ratio became a problem to which there were three main solutions: cropping the picture, stretching the picture, or framing the picture. In the first instance, only a part of the original image is shown, carefully selected, shot-by-shot if the programme maker is sensitive to the issue and has the time and resources for the task, but more likely simply shorn of its top and bottom sections, sometimes cutting off the tops of people's heads. In the second instance, the 4:3 image is simply converted to $16: 9$ at the flick of a switch, stretching the image to fit the new ratio and making people look fatter than they are. In the third, the original ratio is retained, leaving wide black bands at each side of the screen. This is not popular with some programme makers or broadcasters, who can find regular switching between the newly-shot widescreen parts of the programme and the archival footage irritating and believe the viewers do, too, though there is evidence that this perception is changing. Some creative programme makers address this question by graphically 'framing' the original image.

The first major historical documentary series made in widescreen format was the 24-part Cold War (Turner Broadcasting/BBC, 1998), produced by Jeremy Isaacs, the producer of The World At War, and with contributions from many who had worked on that seminal series. The archive footage, an obviously key component of the series, was cropped to fit the widescreen frame and, to this archivist at least, it seemed an unsettling decision. The FIAF (International Federation of Film Archives) Code of Ethics was in development at that time and point 1.6 is unequivocal, even if it is intended to cover presentations of archive footage by archives themselves, rather than in television documentaries:

When providing access to material by programming, projection or other means, archives will seek to achieve the closest possible approximation to the original viewing experience, paying particular attention (for example) to the appropriate speed and the correct aspect ratio. ${ }^{4}$

Surely, it seemed, it must be equally unethical for a documentary to misrepresent an image by only showing part, not all, of it: even if it is being used in an illustrative, rather than evidentiary context; even if it has been accurately used in relation to the commentary; and even if it is a piece of actuality footage and thus not subject to the same aesthetic objections which would arise if a carefully composed shot from a feature film were subject to the same treatment.

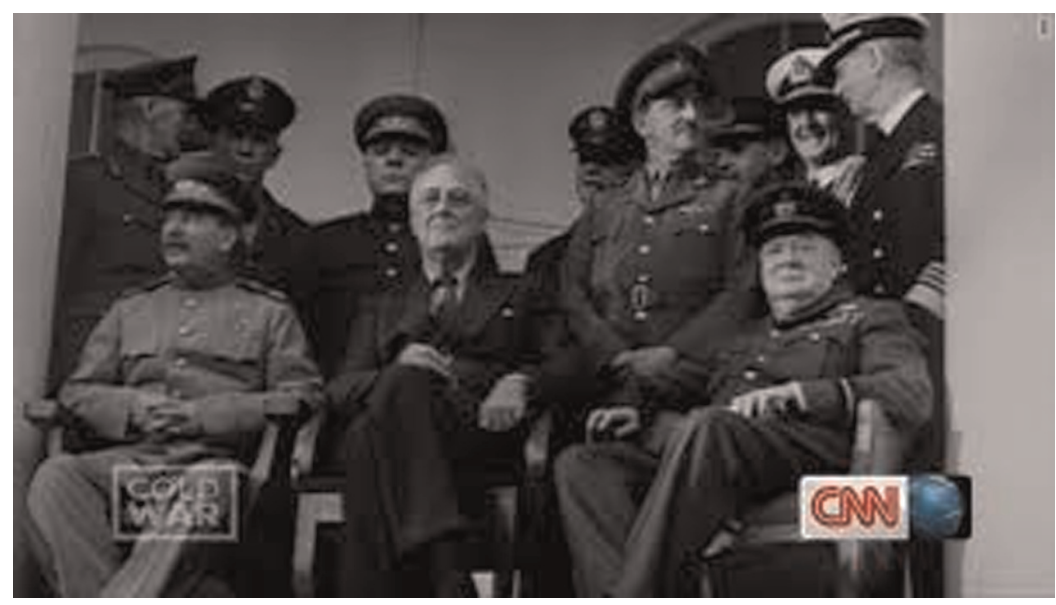

Photo 1. Cold War (Turner Broadcasting/BBC, 1998) 
Indeed, this last point is a clue to one of the most unsettling aspects. It was not so much the fact that the complete image had not been shown which caused the problem. It was that, by rendering it as a widescreen image, it seemed to change its nature according to the previously accepted shorthand of the medium. The practice of cropping the top and bottom of the frame transformed footage previously easily identifiable as factual into something resembling the cinematic and blurred the lines between actuality and reconstruction. This had already happened in the cinema itself. A film like Philip Kaufman's The Unbearable Lightness of Being (1988) used actuality footage (of the 1968 Soviet invasion of Czechoslovakia), intercut with newly shot recreations of the event, containing fictional characters, to highly dramatic effect, making the archive footage look even more dramatic than it already is by putting it into the shape, as well as the context, of a cinema film, but without any attempt to disguise the fact that it was actuality (much of it being monochrome or $16 \mathrm{~mm}$ colour film, with the 'fictional' shots degraded to fit).

In Britain, history documentaries containing archive footage mostly continued to be made in the 4:3 format around the turn of the millennium, as widescreen TV was gradually introduced, but by 2005, when Laurence Rees made Auschwitz: the Nazis and the Final Solution, 16:9 was the standard and the archive film was cropped to fit the interview footage. This practice became commonplace as the widescreen format became accepted as the norm for documentary, which was a result not only of the increasing amount of material being made for transmission on widescreen television, but also of the resurgence of the documentary made for cinema release. Actually, these two things became increasingly interconnected, as feature-length documentaries made for both cinema or festival screenings in the first instance and television transmission thereafter, became the norm, showcased in the UK by strands such as Storyville on the BBC and True Stories on Channel 4. In these circumstances, the fact that archival footage was being cropped to fit the frame in these works simply ceased to matter, if it ever did matter beyond the specialised world of archivists.

Another significant change was underway, as well. In an era where quotation and sampling (often without acknowledgement, at least directly within the body a work) became commonplace in all art forms, helped by digital technologies and the democratisation of media, previous strictures and conventions ceased to apply. If a new piece of music could quote older pieces and use them as an integral part of the new piece, then why not a piece of moving image art, or even 'documentary'? This was particularly evident in the work of a film maker like Adam Curtis, who created his own aesthetic of archival use by illustrating a general thesis with a mixture of factual and fictional source material assembled almost as much as an artistic statement, than as a traditional illustration of the points being made. Starting with Pandora's Box (BBC, 1992), Curtis developed a style in which his own script, read in voice-over by himself, is illustrated by a wide range of archival footage, with very little, if anything, in terms of newly shot material. A series like The Power of Nightmares (BBC, 2004) pushed this aesthetic further by including a diverse and carefully mixed music soundtrack and Curtis eventually transferred his style from broadcast television to art installation/ participatory theatre with the 2009 collaborative work It Felt Like a Kiss. This trend has been continued by a number of productions involving archive footage and music, such as The Big Melt premiered at the 2013 Sheffield Documentary Festival and later transmitted in the BBC's Storyville documentary strand, in which an edited montage of footage restored for a BFI National Archive project about the steel industry was accompanied by a score specially composed by Jarvis Cocker and performed live at the first screening.

Most recently, though, there has emerged a discernible trend in which many film makers have sought creatively to emphasise the diversity of their archival sources and to distance the newly-shot from the archival (and indeed, the archival from different sources) by retaining original aspect ratios, despite the fact that the size of the frame alters regularly within the film. There seem to be two main reasons for this: firstly, the growth of the niche media markets fostered by subscription television services, which has meant that documentaries are now targeted at a specialised rather than a more general audience, who can be expected to have a greater understanding of the medium and not worry about filling every corner of their expensive screen; and secondly, high definition and increasingly large screens have allowed the use of smaller areas within the frame without any loss of detail or quality.

A good example of this is James Lapine's Six By Sondheim (HBO, 2013), which includes archive of memorable songs by the Broadway composer, intercut with more modern performances, as well as a considerable number of interviews with Sondheim himself, from different moments in his career, including a present-day one shot for the documentary. Not only is the amount of research that went in to finding so much material impressive, but the way it is presented is truly 
remarkable. The interviews, covering a period of some six decades, up to and including the present, are cut up and reassembled to create lengthy, flowing, organic statements on particular subjects, giving the impression of a man who has been consistently brilliant throughout his career. Yet, by retaining the original ratios of the different source materials, even framing them in the shape of the television sets of the time they were shot (including using the curved frame edges sometimes resulting from the telerecording process) and by positioning the extracts in different parts of the 16:9 frame, the film maker ensures that the viewer is constantly aware and informed of the different times from which the original material comes, though there are no captions to this effect.

The United States has become the leading producer of feature-length documentaries, large numbers of them featuring the use of film and television archive material. PBS alone has a number of strands to showcase this output - American Experience, POV, Independent Lens, American Masters - while HBO, Sundance, CNN, Netflix and others contribute to the boom. International co-production is also an important part of both the production and distribution process, with Scandinavian public broadcasters, as well as the BBC and Channel 4 in the UK, prominent amongst the main contributors. By and large, the use of archival material has become highly sophisticated, both in aesthetic and contextual terms. One of the great pleasures of watching a series like Ken Burns' The Roosevelts: An Intimate History (PBS, 2014) is the loving care with which stunning monochrome archive is presented - the original frame may have been cropped for widescreen, but every shot has been judged to ensure maximum aesthetic impact from that process. As we have noted, any archival objections on the grounds of ethics have become superfluous.

One of the most interesting recent cases is Andrew Jarecki's The Jinx (HBO, 2015), which utilises archive material from the 1980s, 1990s and 2000s, carefully framed within the high definition 16:9 image and often with 'blurred' edges, top and bottom, so that the timeframe can be effectively conveyed. This even includes material from the brief hybrid 14:9 era, when that ratio was used as a kind of compromise during the transition from 4:3 to 16:9, as it worked reasonably well on both conventional and widescreen televisions.

Despite these exemplary productions, though, the decision on how to present archival footage is too frequently not an aesthetic or ethical one, but an economic one. A production with a limited archival budget, or even just a programme maker without consideration for the issue, can take the simplest and cheapest route, resulting in a proliferation of stretched and distorted images. To the trained eye, this can look horrible, but it is doubtful how much the average viewer really cares, when it is possible to find wrongly-aligned televisions in public places throughout the world. Indeed, the fact that news footage in particular is regularly retransmitted in a distorted form can make it unremarkable when it happens in a documentary, especially one with an investigative subject like The Newburgh Sting (HBO, 2014). Occasionally, though, an otherwise excellent piece can be compromised by a cavalier approach to archive framing, such as Nixon by Nixon: In His Own Words (HBO, 2014), a fascinating piece using previously unreleased tape recordings from Nixon's White House conversations, together with a wealth of archival footage, all of it presented in a distorted ratio, as the 4:3 image is stretched to fit the 16:9 frame.

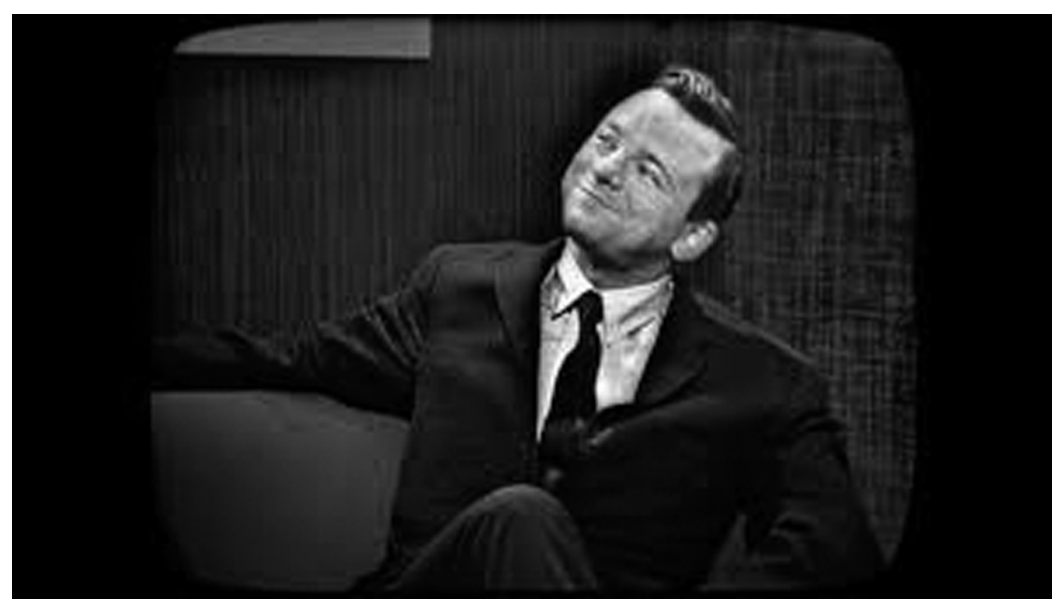

Photo 2. Six By Sondheim (HBO, 2013) 


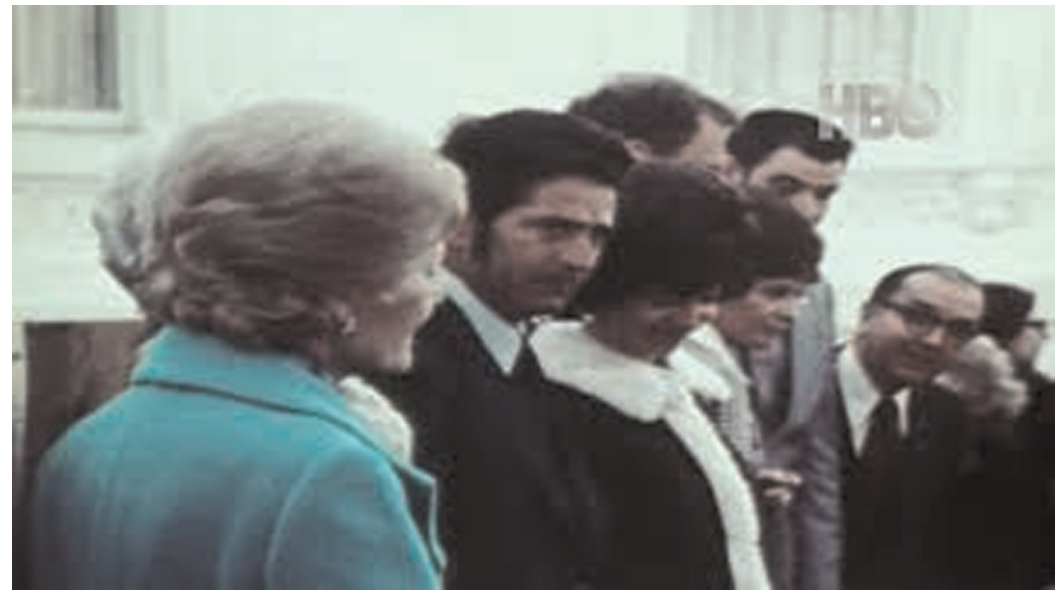

Photo 3. Nixon by Nixon: In His Own Words (HBO, 2014)

As we have seen, though, perspectives change with time. The dynamic in the debate on the use of archival footage in new programmes will always between being entertaining and innovative on the one hand and being accurate and respectful on the other or, at the very least, not being misleading. The most significant breakthroughs will lead change as they make newer ways of presenting footage acceptable, though this may not be immediately apparent and changing attitudes may take time, especially when change has been caused by technological advance, as happened with the introduction of widescreen television. And what should the archivist's role, as custodian of the footage in question, be? In the first instance it can only be advisory - pointing out the provenance and technical specifications of the footage and supplying it to the programme maker in a form as close as possible to its original production, but not attempting to intervene thereafter in the choices as to how it is ultimately used ${ }^{5}$. More important is the obligation on the archivist receiving the newly created programme or film to ensure that it is correctly documented and that any changes made to archival footage contained in it are noted in documentation, in order that any further re-use should not be based on false assumptions created by the new context.

\section{Biography}

Steve Bryant is Senior Curator of Television at the BFI National Archive, a post he has held since 1988. Prior to that he worked at the BBC Film and Videotape Library from 1978-88, latterly as Archive Selector. He is the author of The Television Heritage (BFI, 1989). He was an Executive Council member of the International Federation of Television Archives (FIAT/IFTA) from 1992-2012, being also founding Chair of the Programming and Production Commission (1993-4), General Secretary of the Federation (1994-8 \& 2002-6), and founding Chair and current member of the Television Studies Commission (1998-2002 \& 2006-). He has been a member of the Peabody Awards board since 2011.

5 There has, however, in recent years, been a growth in the number of archivists who have become part of programme production teams, often credited as 'Archive Producer'. These have usually been film researchers with extensive experience of archive use, but have sometimes been archive staff members seconded to the production team. Whichever, this is another reason why greater consideration to the question of aspect ratio can be discerned in more recent productions. 